\title{
How Does Online Information Affect Consumption Decision? \\ -An Empirical Test in the Context of Social Sharing
}

\author{
Chang Liu* Wanfei Wu
}

\author{
School of Economics, Beijing International Studies University, Beijing 100024, China \\ *Corresponding author. Email: echocharlotte@163.com
}

\begin{abstract}
In social media, people can share product information and consumer feelings, which makes the role of social media far beyond social itself. The product information that consumers get on social media has gradually become an important basis for consumer decision-making. In the context of social sharing, how does online information affect consumer decision-making? This paper will discuss the influence of network information on Chinese consumers' decision-making, so as to better understand the characteristics of online consumption behavior and provide the basis for the formulation of enterprise network marketing plans.

Keywords: Online information, social sharing, consumption decision, information credibility
\end{abstract}

\section{INTRODUCTION}

The emergence of instant messaging tools, interactive sharing platforms and other social media provides a platform for people's real-time communication. People can share information in various ways such as text, pictures, video and audio in social media. The spread of these information breaks the shackles of time and space. Information can be widely shared and spread by social media users, and has a far-reaching impact. The process of social media information sharing makes it more convenient for people to share shopping experience, product information and use experience. This makes the impact of social media on people's lives far beyond the social itself, and the product information obtained by consumers on social media has gradually become an important basis for consumer decision-making. IResearch found that $54 \%$ of Chinese social media users will buy because their friends "like" or pay attention to the information of a product, almost twice as much as the overall Asia Pacific region (28\%). In addition, the product information in social media has a greater impact on women's shopping decision-making.

Network information can help consumers evaluate the quality of products, influence the choice of products, and help consumers make purchase decisions. At the same time, more and more enterprises realize the great value of network information in product marketing, and pay more attention to the role of information sharing in marketing. Exploring the influence mechanism of network information on consumer behavior can better explore the online behavior decision-making mode of consumers, and help enterprises grasp the key links of network marketing.

\section{LITERATURE REVIEW}

Jingdong and Nielsen put forward the concept of "social ecommerce". They think that the social function of the network platform embeds elements such as attention, sharing and interaction into the business transaction process, realizes the assistance of commodity purchase and completes the transaction process better. In recent years, more and more scholars regard "network product information" as an important factor affecting consumption. Due to incomplete information, consumers often need to search for information in their consumption behavior. Goldstein et al. (2010) [1]believed that consumers would evaluate a series of attributes of products according to the information obtained before making decisions, and finally get the overall evaluation and make decisions based on it. Product information on the Internet can reduce the risk, reduce the cost of information collection of consumers (Floyd et al., 2014) [2], and significantly affect the purchase intention (Jin and Phua, 2014) [3]. According to the 2016 report of China Internet Information Center (CNNIC), about $77.5 \%$ of consumers make choices and decisions based on online word-of-mouth. Research by Awad \& Ragowsky (2008) found that product information shared online can affect consumers' perceived credibility, thus affecting online purchase intention. Zhao Jianbin's (2018) research on the online brand community shows that product interaction information and interpersonal interaction information have a positive impact on the purchase intention of diving customers. Studies such as Bickartb (2001) [4], Xue (2004) [5]and Senecal (2004) [6]found that the third-party review websites had more influence on consumers than the public praise evaluation on the official websites. Hajli (2012) [7]found that social 
recommendation affects trust and perceived usefulness, and thus consumption intention. Lu Yunfan et al. (2014) found that online communication of social network users seeks information, thus affecting online shopping willingness. Research by Adjei et al. (2010) [8]shows that the higher the quality of community interaction information, the stronger the consumers' purchase intention of brand products.

Previous studies have shown that there is a correlation between social media information sharing and consumers' purchase decisions. However, there are many qualitative, but not enough quantitative studies, and there is a lack of special discussion on user generated content in social media. In the context of social networks, how does online information affect consumer decision-making? In this paper, we will integrate the existing research dimensions to explore the role of network information in Chinese consumer decision-making process.

\section{MODEL CONSTRUCTION AND RESEARCH HYPOTHESIS}

Hovland (1953) [8]thinks that information source, information itself and information receiver are three factors that affect information perception. Cheung and Thadani (2012) believe that the type, qualification, motivation, social relationship and similarity of information can affect the credibility of online word-ofmouth. With the continuous development of social media, information communication channels have diversified characteristics. Zhang Yingren (2004) believes that information credibility should not only be measured from the source, but also fully consider the factors of communication channels. Based on the above conclusions, this paper discusses the influence of the characteristics of the sharer, the information, the receiver and the channel on the purchase decision-making of consumers.

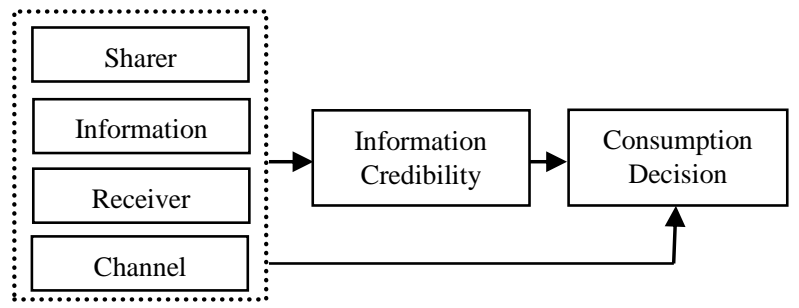

Figure1 Theoretical Model

In this paper, we use Smith (2002) model to study the impact of product evaluation information on purchase decision-making in virtual community, and build a theoretical model with information credibility as an intermediary variable. Based on this, we propose the following assumptions:

H1: Online information has a positive impact on consumption decision.

$\mathrm{H} 2$ : Information Credibility plays an intermediary role in the positive impact of network information on consumer behavior decision-making.

\subsection{Information sharers}

According to Bansal and Voyer (2000) [9], information receivers are more inclined to believe in information provided by reliable sources. Gilly (1998) [10]Showed that the more professional the information source is, the greater its impact on the receiver. Brown \& Reingen (1987) believed that similar sharers and receivers are more likely to have a sense of resonance and identity, so similarity will enhance mutual trust. Gilly (1998) believes that the more similar the information source and the receiver are, the greater the impact will be. Brown J. (2007) [11] Found that the similarity between the theme of virtual community and the interest of consumers will affect consumers' evaluation of information value. Smith (2002) [12]shows that the relationship strength between information sender and information receiver affects the effect of recommendation information on consumer decisionmaking. Sweeney et al. (2007) [13]shows that strong relationships are more likely to affect the willingness of information recipients to consume. Keller (2007) believed that the understanding and trust between the information sharer and the receiver can enhance the credibility of the network information.

Research by Harben (2004)[14]shows that when consumers think that information publishers publish information in a paid way, they choose not to trust the information. When consumers think that information dissemination by information publishers is free, they choose to believe the authenticity of the information. Based on the above analysis, the following assumptions are proposed:

H3: The characteristics of information sharers has a positive impact on consumption decision.

H3a: The professionalism of information sharers has a positive impact on consumption decision.

$\mathrm{H} 3 \mathrm{~b}$ : The similarity between the information sharer and the receiver has a positive impact on consumption decision. H3c: The intensity of the relationship between the information sharer and the receiver has a positive impact on consumption decision.

H3d: The communication motivation of information sharers has a positive impact on consumption decision.

\subsection{Information characteristics}

High quality information can better reflect the real attributes of the product, so it will be more trusted by the receiver and more influential on their purchase decisions. Chateijee (2001) shows that because consumers equate the evaluation quantity with the sales volume of products, they try to reduce the uneasiness caused by their purchase decisions by reading a large number of evaluation information published by others. Lai Shengqiang et al. (2011) believed that the quality of comment content affects consumers' product attitude and purchase intention. Research by Godes and Mayzlin et al. (2004) [15], Park et al. (2007) [16], Yang Shuang et al. (2013) explored the 
impact of online comment quality on consumers' purchase decision from different perspectives. Research by Juliet et al. (2017) shows that both the quality of reviews and the rank of reviewers have a positive impact on consumers' purchase intention. Rosenthal (1971) [17] believes that the audience's evaluation of the credibility of information depends on the specificity and verifiability of information content. The empirical research of Sun Chunhua (2009) shows that the credibility of information is directly proportional to the amount of information. Based on the above analysis, this paper puts forward the hypothesis:

H4: Information characteristics positively affect consumption decision.

H4a: Information quality is positively related to consumption decision.

$\mathrm{H} 4 \mathrm{~b}$ : The quantity of information is positively related to consumption decision.

\subsection{Channel}

When the individual's dependence on the channel increases, they will pay more attention to the information provided by the channel. Therefore, channel characteristics become an important factor affecting the effect of information sharing. The audience's evaluation of a channel's reputation has a lot to do with their frequency of using the channel (Wanta \& Yu Wei, 1994). The more trust the audience has in a particular channel, the easier it is to rely on it to obtain information, and the easier it is to believe the information shared in the channel. Basso et al. (2001) [18] confirmed that those synchronous communication media that can "provide feedback opportunities" can improve trust in online sales personnel. Bickart and Schindler (2001) [19]pointed out that information from the forum would generate more interest in the product than on the company's website. Park (2008) [20] analyzed that the reputation and information dissemination direction of the website will affect the effect of online word-of-mouth communication. When the information dissemination is real-time interaction between the two sides, the effect of information dissemination is better. A survey conducted by the first financial daily also showed that respondents believed that the credibility of product information shared on Weibo, Wechat or other social media was second only to that recommended by friends and family members. Based on the above analysis, this paper puts forward the hypothesis:

H5: The characteristics of communication channels positively affect consumption decision.

H5a: The interaction degree of information channels is positively related to consumption decision.

$\mathrm{H} 5 \mathrm{~b}$ : The reputation of information channels is positively related to consumption decision.

\subsection{Information receiver}

In the process of social information sharing, different information receivers will show different responses to the same information. Antil (1984) found that there was a significant relationship between product involvement and information processing. Consumers with a high degree of inclusion have a strong desire to deeply understand product information and are more inclined to deeply process information. Frank \& John (1991) found that different products produce different levels of involvement. Hawkins (1998) pointed out that when the product involvement degree is low, consumers tend to omit information search or alternative brand price and buy directly. On the contrary, when the product involvement degree is high, consumers will pay more energy and time to search for word-of-mouth information. However, as more and more word-of-mouth information is collected, the same products or services will be seriously considered and compared. At this time, visitors will be cautious and skeptical about the received online word-of-mouth. Wang Quansheng (2010) believes that high interpersonal susceptibility customers are very sensitive to other people's expectations or suggestions, and will pay special attention to other people's opinions and how others judge their purchase behavior, while low interpersonal susceptibility customers are not sensitive to other people's expectations and suggestions, and are not susceptible to other people's information. Bansal \& Voyer (2000) believes that the more professional the information receiver is, the weaker the word-of-mouth effect will be. On the contrary, word-ofmouth has a huge influence on those consumers who are less professional. However, Punj and Staelin (1983) hold the opposite view. They believe that word-of-mouth has a more obvious impact on consumers with high professionalism than consumers with low professionalism. Voyer (1999) explains that the higher the knowledge level of the receiver, the more active the receiver is in finding and referring to the comments on the Internet, so it is inevitably affected by word-of-mouth. Research by Fan and Chen (2009) shows that in the network environment with insufficient product information, the trust tendency of the receiver will significantly affect consumers' perception of credibility.

Based on the above analysis, this paper puts forward the hypothesis:

H6: The characteristics of information receiver positively affect consumption decision.

H6a: The recipient's professionalism is positively related to consumption decision.

H6b: The trust tendency of information receiver is positively related to consumption decision.

H6c: The product involvement of the information receiver is positively related to consumption decision. 


\section{EMPIRICAL RESULTS}

Based on the existing research, this paper designs 13 items of information sharing characteristics, 7 items of information characteristics, 4 items of channel characteristics, 7 items of information receiver characteristics, 4 items of information credibility and 4 items of consumer decision.

The data were collected by questionnaire. The first part of the questionnaire is information sharing behavior research scale, which mainly includes 12 parts: information sharer's professionalism, relationship strength, communication motivation, similarity, information quantity, information quality, receiver's trust tendency, receiver's professional ability, receiver's product involvement, channel interaction degree, channel reputation, credibility and consumer purchase decision. The second part of the questionnaire is about the basic situation of consumers, mainly including gender, age, education, income. 502 questionnaires were collected and 483 were valid.

\subsection{The influence of network information on consumers' purchase decision}

In this paper, smart pls 3.0 is used to test the load coefficient and path coefficient of the model by bootstrapping. The results of factor load coefficient show that the measurement variables have a high degree of interpretation to the prediction variables. The hypothesis test results show that the t-value of channel interaction, channel reputation, information quantity, information quality, product involvement of the receiver, communication motivation of the sharer and professional ability of the sharer are all greater than 1.96, and p-value < 0.05 . Therefore, the original hypothesis holds that the above aspects can positively affect the purchase decision. However, the positive effects of receiver's professional ability, receiver's trust tendency, relationship strength, and the similarity between the sharer and the receiver on consumption decision-making are not valid.

Table 1 Bootstrapping test results of social information sharing and consumption decision

\begin{tabular}{|c|c|c|c|}
\hline & coefficient & P value & Whether the hypothesis is supported \\
\hline channel interaction & 0.100 & 0.018 & YES \\
\hline channel reputation & 0.083 & 0.017 & YES \\
\hline information quantity & 0.149 & 0.000 & YES \\
\hline information quality & 0.186 & 0.000 & YES \\
\hline involvement of the receiver & 0.080 & 0.020 & YES \\
\hline recipient professionalism & 0.064 & 0.069 & NO \\
\hline receiver's trust tendency & -0.04 & 0.341 & YES \\
\hline motivation of the sharer & 0.104 & 0.026 & YES \\
\hline professionalism of the sharers & 0.175 & 0.000 & NO \\
\hline relationship strength & 0.038 & 0.386 & NO \\
\hline $\begin{array}{c}\text { the similarity between the sharer and the } \\
\text { receiver }\end{array}$ & 0.069 & 0.103 & \\
\hline
\end{tabular}

\subsection{The influence of network information on information credibility}

According to table 2, we can see that the positive influence of channel interaction, information quantity, information quality, product involvement of the receiver, trust tendency of the receiver, motivation of the sharer, professional ability of the sharer and relationship strength of the sharer on the credibility is significant, so the original hypothesis are true. However, the positive effects of channel reputation, receiver's professional ability, and the similarity between the sharer and the receiver on information credibility are not established.

Table 2 Bootstrapping test results of social information sharing and credibility

\begin{tabular}{|c|c|c|c|}
\hline & coefficient & P value & Whether the hypothesis is supported \\
\hline channel interaction & 0.102 & 0.017 & YES \\
\hline channel reputation & 0.034 & 0.356 & NO \\
\hline information quantity & 0.117 & 0.006 & YES \\
\hline information quality & 0.117 & 0.044 & YES \\
\hline involvement of the receiver & 0.084 & 0.01 & YES \\
\hline recipient professionalism & 0.053 & 0.102 & NO \\
\hline
\end{tabular}




\begin{tabular}{|c|c|c|c|}
\hline receiver's trust tendency & 0.094 & 0.020 & YES \\
\hline motivation of the sharer & 0.154 & 0.000 & YES \\
\hline professionalism of the sharers & 0.125 & 0.005 & YES \\
\hline $\begin{array}{c}\text { relationship strength } \\
\text { the similarity between the sharer and } \\
\text { the receiver }\end{array}$ & 0.103 & 0.031 & YES \\
\hline
\end{tabular}

In order to identify whether credibility plays an intermediary role, it is necessary to compare the change of path coefficient of influence of network information on consumption decision-making after adding credibility as an intermediary variable. The empirical results show that the path coefficient of independent variables for purchase decision is lower than before, but it is not significant and not zero, and the path coefficient of credibility for

\section{CONCLUSION}

Based on the empirical results, the following conclusions can be drawn:

Firstly, the professionalism and communication motivation of information sharers have a significant impact on consumer purchase decision-making and information credibility, while the similarity and relationship strength between information sharers and information receivers have no significant impact on consumer decision-making. It can be seen that the information delivered by professional information sharers such as opinion leaders and information considered objective rather than marketing by the audience often has a higher impact, and the "effectiveness" of information will not be affected by the similarity or relationship strength of information receivers and information sharers. Therefore, in network marketing, we should pay more attention to the role of opinion leaders and related professionals.

Secondly, the degree of channel interaction has a significant impact on consumers' purchase decisionmaking and credibility, and channel reputation has a significant impact on consumers' purchase decisionmaking, but the hypothesis of positive impact with credibility is not true. Consumers are more objective when they view channel reputation and product information, because the reputation of channel itself does not represent the quality of information.

Thirdly, the quality and quantity of information have a significant impact on consumers' purchase decisionmaking and credibility. When consumers read the network information, they will judge the authenticity and objectivity of the information. The larger the amount of information, the more clearly consumers can understand the product situation, and enhance consumers' perception of credibility. purchase decision is significantly not equal to zero. Therefore, we come to the following conclusion: in the process of social information sharing, each factor not only directly affects the consumer's purchase decision, but also indirectly influences the consumer's purchase decision through the intermediary role of credibility, which plays a part of intermediary role between independent variables and dependent variables.

\section{ACKNOWLEDGMENT}

This work was supported by National Social Science Foundation of China (15CJY056).

\section{REFERENCES}

[1]GOLDSTEIN W, EINHORN H, 2010. Expression theory and the preference reversal phenomena [J]. Psychological review, 94(2) : 236-254

[2] FLOYD K, FRELING R, ALHOQAIL S, et al. How online product reviews affect retail sales: a meta-analysis [J]. Journal of Retailing, 2014, 90(2) : $217-232$.

[3] JIN S A, PHUA J. Following celebrities' tweets about brands: the impact of twitter-based electronic wordof-mouth on consumers' source credibility perception, buying intention, and social identification with celebrities [J]. Journal of Advertising, 2014, 43(2) : $181-$ 195.

[4] Bickartb , Schindler M . Internet Forums as Influential Sources of Consumer Information [ J ] . Journal of Interactive Marketing, 2001, $15(3): 31-40$

[5] Xue F. , Phelps J . E . Internet-facilitated Consumer-to-Consumer Communication: The Moderating Role of Receiver Characteristics [ J ] . International Journal of Internet Marketing and Advertising, 2004, 1(2) :121-136

[6] Senecal S., Nantel J. The Influence of Online Product Recommendations on Consumers'Online Choices 
[J]. Journal of Retailing，2004， 80(2):159-169

[7] HAJLI M.Social commerce adoption model[C].The UK academy of information systems conference.UK : University of Oxford, 2012.

[8] Hovland C . I . , Janis I . L . , Kelly H. H. Communication and Persuasion $[\mathrm{M}]$. New Haven: Yale University Press, 1953

[9] Bansal H. S., Voyer P. A. Word-of-Mouth Processes Within a Services Purchase Decision Context [J]. Journal of Service Research, 2000, 3(2) :166167

[10] Gilly, M.C., Graham, J.L., Wolfnbarger, M.F., Yale, L.J. A Dyadic Study of Interpersonal Information Search [J]. Journal of the Academy of Marketing Science, 1998, (2): $83-100$

[11] Brown J., Broderick A J., Lee N., Word of Mouth Communication Within Online Communities: Conceptualizing the On-line Social Network[J]. Journal of Interactive Marketing, 2007, (21)3: 2-20

[12] Smith, D.N. Trust Me, Would I Steer You Wrong? The Influence of Peer Recommendations within Virtual Communities[D]. University of Illinois at Chicago, 2002

[13] Sweeney J.C., Soutar G.N., Mazzarol T. Factors in Fluencing Word of Mouth Effectiveness: Receciver Perspectives[J]. European Journal of Marketing, 2007, 42(3-4): 344-364

[14] Harben B., Kwon W.S. Predicting Consumers' CauseBrand Alliance Attitude: The Influence of Cause Involvement, Message Source, Perceived Motivations, and Cause-Brand Fit $[\mathrm{J}]$. Dissertations \&Theses - Gradworks, 2009, 14(2):39-41

[15] Godes D . , Mayzlin D . Using Online Conversations to Study World-of-Mouth Communication [J]. Marketing Science, 2004, 23(4): 545-560

[16] Park D. H. , Lee J., Han I. The Effect of Online Consumer $\mathrm{R}$ eviews on Consumer Purchasing Intention:The Moderating Role of Involvement $[\mathrm{J}]$. International Journal of Electronic Commerce, 2007, 11(4):125-148

[17] Rosenthal M.L. A Multivariate Analysis of Responsiveness Consumers: A Pilot to Dissatisfaction[J]. Journal of Academy Marketing Science, 1971, 15(3):27-34

[18] Basso A, Goldberg D, Greenspan S., Weimer D. First Impressions: Emotional and Cognitive Factors Underlying Judgments of Trust E-commerce[C]. In Proceedings of the 3rd ACM Conference on Electronic Commerce, Tampa, FL, USA, 2001, 137-143

[19] Bickart B., Schindler R. Internet Forumsas Influential Sources of Consumer Information[J]. Journal of Interactive Marketing, 2001, 15(3):31-40.

[20] Park D, Lee J., E-WOM Overload and its Effect on Consumer Behavioral Intention Depending on Consumer Involvement $[\mathrm{J}]$. Electronic Commerce Research and Applications, 2008, 7(4): 386-398. 